\title{
Mechanistic Basis of Resistance to PCBs in Atlantic Tomcod from the Hudson River
}

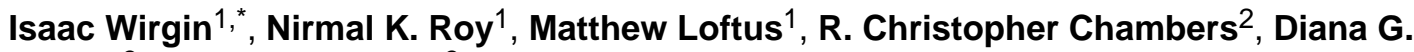 \\ Franks ${ }^{3}$, and Mark E. Hahn ${ }^{3}$ \\ ${ }^{1}$ Department of Environmental Medicine, New York University School of Medicine, 57 Old Forge \\ Road, Tuxedo, NY 10987, USA. \\ ${ }^{2}$ Howard Marine Sciences Laboratory, Northeast Fisheries Science Center, National Oceanic and \\ Atmospheric Administration Fisheries Service, 74 Magruder Road, Highlands, NJ 07732, USA. \\ ${ }^{3}$ Biology Department, Woods Hole Oceanographic Institution, 45 Water Street, Woods Hole, MA \\ 02543, USA.
}

\section{Abstract}

\begin{abstract}
The mechanistic basis of resistance of vertebrate populations to contaminants, including Atlantic tomcod from the Hudson River (HR) to polychlorinated biphenyls (PCBs), is unknown. HR tomcod exhibited variants in the aryl hydrocarbon receptor 2 (AHR2) that were nearly absent elsewhere. In ligand-binding assays, AHR2-1 protein (common in the HR) was impaired as compared to widespread AHR2-2 in binding TCDD (2,3,7,8-tetrachlorodibenzo-p-dioxin) and in driving expression in reporter gene assays in AHR-deficient cells treated with TCDD or PCB126. We identified a six-base deletion in AHR2 as the basis of resistance and suggest that the HR population has undergone rapid evolution, probably due to contaminant exposure. This mechanistic basis of resistance in a vertebrate population provides evidence of evolutionary change due to selective pressure at a single locus.
\end{abstract}

From 1947 to 1976, two General Electric facilities $315 \mathrm{~km}$ upstream of the mouth of the Hudson River (HR) released 590,000 kg of polychlorinated biphenyls (PCBs) into the river. Atlantic tomcod Microgadus tomcod is an abundant, bottom-dwelling, and resident finfish of the HR (1). Levels of PCBs and polychlorinated dibenzo-p-dioxins/furans (PCDD/Fs) [including the most toxic congener, 2,3,7,8-tetrachlorodibenzo- $p$-dioxin (TCDD)] in tomcod livers from the HR and Hackensack River in the western HR estuary are among the highest known in nature (2). Most toxicities from halogenated aromatic hydrocarbons (HAHs) such as PCBs and PCDD/Fs and induction of xenobiotic metabolizing enzymes such as cytochrome P4501A (CYP1A) are mediated by the aryl hydrocarbon receptor (AHR) (3). The pathway is activated when ligands bind cytoplasmic AHR at its ligand-binding domain (LBD), and the AHR-ligand complex translocates to the nucleus, where it binds dioxin response elements in the promoter of genes such as CYP1A and activates their transcription. There are two AHRs in fishes (4), of which AHR2 is the more functionally active (5). CYP1A expression is 100-fold less sensitive to induction by PCBs and TCDD in all tissues $(6,7)$ and life stages of tomcod (1) from throughout the HR (8)as compared to tomcod from cleaner locales. Decreased inducibility is heritable to at least the $\mathrm{F}_{2}$ generation, is co-

\footnotetext{
Copyright 2011 by the American Association for the Advancement of Science; all rights reserved.

"To whom correspondence should be addressed. Isaac.wirgin@nyumc.org .

Supporting Online Material www.sciencemag.org/cgi/content/full/science.1197296/DC1 Materials and Methods Fig. S1 Tables S1 to S3 References and Notes
} 
dominant (fig. S1), and co-occurs with a 100-fold reduction in the sensitivity of HR tomcod to early-life stage toxicities (1).

We characterized full-length AHR2 cDNAs by sequencing overlapping AHR2 amplicons in 10 tomcod from each of three locales: the HR and two reference locales, one distant from [the Miramichi River (MR) in New Brunswick, Canada] and one proximal to [Shinnecock Bay (SB) in New York] the HR. Four of five polymorphisms that were observed showed fixed differences between tomcod from the HR and the other locales. These were two synonymous base substitutions; one nonsynonymous base substitution [nucleotide (nt) 3274 in exon 11: A (Asn) in the HR; T (Tyr) in SB and the MR]; and a six-nt deletion (nts 1314 to 1319 in exon 10; TTCCTC) in HR fish that resulted in a two-amino acid (Phe-Leu) deletion located 43 amino acids downstream of the amino terminal of the AHR2 LBD.

We screened for the AHR2 deletion and the nt 3274 base substitution in tomcod from larger collections ( $n=31$ to 62 specimens per site) from seven Atlantic Coast estuaries ranging from the HR to the St. Lawrence (Fig. 1, A and B). The AHR2-1 allele [with the 6-base pair (bp) deletion and nt 3274 substitution] was detected only in tomcod from the four southernmost populations [frequencies were as follows: $99 \%$ in the HR; $92 \%$ in the Hackensack River, New Jersey (western HR estuary); $6 \%$ in the Niantic River, Connecticut; and 5\% in SB]. Populations more distant from the HR were monomorphic for AHR2-2; in the HR estuary, AHR2-2 was seen only in heterozygotes. In the Niantic River and SB, near the HR, AHR2-1 was observed only in heterozygotes. The presence of AHR2-1 at low frequencies in tomcod from these two cleaner nearby estuaries within $150 \mathrm{~km}$ of the mouth of the HR suggests that AHR2-1 was present as a standing variant at low frequency in the HR before anthropogenic disturbances. The presence of AHR2-2 at low frequencies in the HR suggests that its frequency was altered recently through selection.

To evaluate the functional significance of the variant AHR2 alleles, we screened a subset of specimens from these estuaries for sequence variation at the selectively neutral mitochondrial DNA control region (mtDNA CR). The HR population exhibited the most haplotypes $(n=15)$ and had the greatest haplotypic diversity (0.853) (table S1), which is consistent with recent Pleistocene glaciation. Thus, any broad-scale mortality episode that may have occurred in the HR because of contaminants did not result in a genetic bottleneck. Haplotype frequencies between the main stem of the HR and the Hackensack River were similar, consistent with an absence of barriers to gene flow between the two locales in the HR estuary. In contrast, significant haplotype frequency differences $(P<0.01)$ were observed among all U.S. collections (except between the HR and Squamscott River), consistent with the reproductive isolation of these populations and the year-round residency of tomcod in their natal estuaries (Fig. 2 and table S1). The extent of genetic differentiation in haplotype frequencies between the HR and its most proximal neighbors did not approach that seen at the AHR2 locus. Furthermore, a direct association was observed between mtDNA and geographic distances (Mantel's test, $R=0.583 ; P=0.013$ ), which is consistent with patterns of mtDNA diversity among populations reflecting stochastic mutation and genetic drift. Furthermore, we sequenced 901 bp of AHR2 intron 8, exon 9, and intron 9 immediately upstream of the deletion polymorphism in exon 10 in a subset of specimens from five of the seven collections ( $n=34$ HR specimens and 29 from other rivers) and failed to detect any additional polymorphisms.

The full-length in vitro-synthesized AHR2-1 and AHR2-2 proteins (Fig. 3A, inset) were evaluated for their abilities to bind $\left[{ }^{3} \mathrm{H}\right]$-radiolabeled TCDD in ligand-binding assays. The AHR2 proteins differed in their abilities to bind $\left[{ }^{3} \mathrm{H}\right]$ TCDD (Fig. 3A). AHR2-1 was approximately one-third as effective in binding $\left[{ }^{3} \mathrm{H}\right]$ TCDD as was AHR2-2 (Fig. 3B). Saturation binding analysis demonstrated that the AHR2-2 protein bound $\left[{ }^{3} \mathrm{H}\right] \mathrm{TCDD}$ with 
an apparent equilibrium dissociation constant $\left(K_{\mathrm{d}}\right)$ of $1.27 \mathrm{nM}$. In contrast, the specific binding to the AHR2-1 protein was lower atall concentrations of $\left[{ }^{3} \mathrm{H}\right] \mathrm{TCDD}$, and a $K_{\mathrm{d}}$ could not be calculated because a plateau was not achieved under the conditions of the assay (Fig. $3 \mathrm{C})$. The $K_{\mathrm{d}}$ value for AHR2-1 is likely to be near or above the highest concentration of free $\left[{ }^{3} \mathrm{H}\right]$ TCDD present in our assay $(\sim 7 \mathrm{nM})$, suggesting that the affinity of AHR2-1 for TCDD is at least five times lower than that of AHR2-2. Differences in ligand affinity of this magnitude can result in much larger differences in sensitivity to toxicants in vivo (9)

We compared the variant AHR2 proteins in reporter gene assays in AHR-deficient murine c12 hepatoma cells. Cells were transfected with $p S B-A H R 2$ (AHR2-2) or $p H R$-AHR2 (AHR2-1), tomcod ARNT1, and the firefly luciferase reporter gene construct $p G u d l u c$ 6.1, and treated with graded doses of TCDD or PCB126. The complete dose-response curves for the two AHR2 proteins were compared for each chemical by counting the number of doses at which the mean response for AHR2-1 was smaller than for AHR2-2. The difference was significant (binomial test) for each of the two chemicals: for TCDD, seven of eight (7/8) doses $(P=0.035)$, and for PCB $126,8 / 8$ doses $(P=0.004)$ (Fig. 4A). For both treatments, cells transfected with $p S B-A H R 2$ were significantly more responsive than those transfected with $p H R-A H R 2$.

To compare the effects of the 6-bp deletion and of the nt 3274 single-nucleotide polymorphism (SNP) on TCDD-induced gene expression, $p S B$ - $A H R 2$ was mutated to have an $A$ at nt 3274 in $p S B-A-A H R 2$, and $p H R-A H R 2$ was mutated to have a T at nt 3274 in $p H R-T-A H R 2$. Both $p S B-A H R 2$ and $p S B-A-A H R 2$ were effective in driving reporter gene expression in TCDD-treated cells (Fig. 4B). In contrast, TCDD failed to induce significant luciferase expression in either $p H R-A H R 2-$ or $p H R-T-A H R 2-$ transfected $\mathrm{c} 12$ cells. This indicates that the 6-bp AHR2 deletion, rather than the nt 3274 SNP, was the basis of resistance to inducible gene expression.

The mechanistic basis of variation in sensitivities to polycyclic aromatic hydrocarbons (PAHs) and TCDD between inbred mouse strains (10) and among avian species $(9,11)$ resulted from one or two amino acid substitutions at critical residues within the AHR LBD that reduce the binding affinities to ligand. We also observed substantially reduced binding affinity for TCDD in resistant tomcod, but this did not result from variation within the LBD. It is possible that the two-amino acid deletion altered the conformation of AHR2 and thus the accessibility of ligand to the LBD. Consistent with this possibility, the region of AHR2 in which this deletion is located is the site of interaction with the immunophilin-related chaperone AIP/Ara9/XAP2, which stabilizes AHR and enhances its ability to bind ligand and activate transcription $(12,13)$. Thus, altered AHR protein stability may also contribute to the resistant phenotype.

Resistance to TCDD, PCBs, and PAHs has also been observed in populations of Atlantic killifish, Fundulus heteroclitus, from three Atlantic Coast estuaries contaminated with aromatic hydrocarbons $(14,15)$. Sensitivity to PCB126-induced embryonic toxicity and CYP1A expression in $\mathrm{F}_{1}$ and $\mathrm{F}_{2}$ killifish embryos whose parents were collected at different locales varied $>10,000$ fold and was adaptive to levels of PCBs at their residence sites (16). The resistance response was heritable between the $F_{1}$ and $F_{2}$ generation in most but not all killifish populations (16). Resistance in killifish was unrelated to altered expression of components of the AHR pathway (17). AHR1 (18) and AHR2 (19) showed evidence of selection, but variants were functionally indistinguishable in vitro. Multiple mechanisms of resistance to HAHs may exist among fish populations, including mechanisms that are both AHR-dependent and AHR-independent. Although our results indicate a primary role for the AHR2 deletion in the resistance of HR tomcod to HAHs, we cannot exclude the possibility that AHR-independent mechanisms may also contribute to the resistant phenotype. 
Our results indicate that recent evolution has occurred in the HR population as a result of selective pressures. The bioaccumulation of high levels of persistent HAHs, minimal gene flow with populations in nearby estuaries (20), panmixia within the HR, and strong selective pressures lead us to conclude that HR tomcod have experienced rapid evolutionary change in the 50 to 100 years since the release of these contaminants. Our results indicate that resistance can be due to one structural change in the coding region of a single gene and that evolutionary change in anthropogenically challenged natural populations can be rapid. AHR2 is probably a sensitive target for selection because of its regulatory role in the metabolism of contaminants and in the activation of most HAH-induced toxicities. It would have been informative to date the onset of resistance in the HR population, but the only archived samples collected before the introduction of contaminants were preserved in formalin, which makes analyses of their DNA problematic.

Rapid evolutionary change at AHR2 most likely resulted from selective pressure against sensitive phenotypes of early life stages of tomcod: acute embryo mortality or increased prevalence of malformations that were incompatible with survival. Resistance is believed to be accompanied by evolutionary costs that are manifest either as heightened sensitivity to other stressors or impaired performance in common life history traits (21). We have yet to detect evolutionary costs in resistant tomcod, but given the role of AHR in binding endogenous ligand(s) and its pleiotrophic effects in AHR knockout models, it is likely that costs do exist.

\section{Supplementary Material}

Refer to Web version on PubMed Central for supplementary material.

\section{Acknowledgments}

We acknowledge support of R01ES015447, P42ES007381, ES00260, the Hudson River Foundation, and the Northeast Fisheries Science Center. We thank M. Mattson, K. Sullivan, D. Danila, S. Courtenay, C. Burnett, L. Upchurch, P. Roy, S. Karchner, and A. Nadas for assistance. Accession nos. FJ215751 to FJ215756.

\section{References and Notes}

1. Wirgin, II.; Chambers, RC. In: Waldman, JR.; Limburg, KE.; Strayer, D., editors. Hudson River Fishes and their Environment; American Fisheries Society Symposium 51; Bethesda, MD: American Fisheries Society; 2006. p. 331-364.

2. Fernandez MP, Ikonomou MG, Courtenay SC, Wirgin II. Environ. Sci. Technol. 2004; 38:976. [PubMed: 14998007]

3. Ma Q. Curr. Drug Metab. 2001; 2:149. [PubMed: 11469723]

4. Hahn ME, Karchner SI, Shapiro MA, Perera SA. Proc. Natl. Acad. Sci. U.S.A. 1997; 94:13743. [PubMed: 9391097]

5. Prasch AL, et al. Toxicol. Sci. 2003; 76:138. [PubMed: 12883077]

6. Yuan Z, Courtenay S, Wirgin I. Aquat. Toxicol. 2006; 76:306. [PubMed: 16313980]

7. Wirgin II, et al. Mar. Environ. Res. 1992; 34:103.

8. Yuan Z, Courtenay SC, Chambers RC, Wirgin I. Environ. Health Perspect. 2006; 114:77. [PubMed: 16393662]

9. Karchner SI, Franks DG, Kennedy SW, Hahn ME. Proc. Natl. Acad. Sci. U.S.A. 2006; 103:6252. [PubMed: 16606854]

10. Poland A, Palen D, Glover E. Mol. Pharmacol. 1994; 46:915. [PubMed: 7969080]

11. Head JA, Hahn ME, Kennedy SW. Environ. Sci. Technol. 2008; 42:7535. [PubMed: 18939598]

12. LaPres JJ, Glover E, Dunham EE, Bunger MK, Bradfield CA. J. Biol. Chem. 2000; 275:6153. [PubMed: 10692406] 
13. Meyer BK, Perdew GH. Biochemistry. 1999; 38:8907. [PubMed: 10413464]

14. Van Veld, PA.; Nacci, DE. The Toxicology of FIshes. Di Giulio, RT.; Hinton, DE., editors. CRC Press; Boca Raton, FL: 2008. p. 597-641.

15. Wirgin I, Waldman JR. Mutat. Res. 2004; 55:1897.

16. Nacci DE, Champlin D, Jayaraman S. Estuaries Coasts. 2010; 33:853.

17. Powell WH, Bright R, Bello SM, Hahn ME. Toxicol. Sci. 2000; 57:229. [PubMed: 11006353]

18. Hahn ME, Karchner SI, Franks DG, Merson RR. Pharmacogenetics. 2004; 14:131. [PubMed: 15077014]

19. Hahn, ME., et al. Mechanism of PCB and Dioxin Resistance in Fish in the Hudson River Estuary. Role Of Receptor Polymorphisms. Hudson River Foundation; New York: 2005.

20. Able, KA.; Fahay, MP. The First Year of Life of Estuarine Fishes in the Middle Atlantic Bight. Rutgers Univ. Press; Rutgers, NJ: 1998.

21. Van Straalen, NM.; Hoffmann, AA. Demography of Ecotoxicology. Wiley; New York: 2000. p. 147-161. 




Fig. 1.

(A) Frequencies of variant AHR2-1 and AHR2-2 alleles in tomcod from Atlantic coast estuaries. $n$ indicates the number of specimens analyzed per estuary. (B) Restriction fragment length polymorphism analysis of variant tomcod AHR2 alleles. Lanes 1 to 7 contained the AHR2-1 allele (with the 6-bp deletion), and lanes 8 to 14 contained the AHR2-2 allele (without the 6-bp deletion). M, molecular weight marker. 

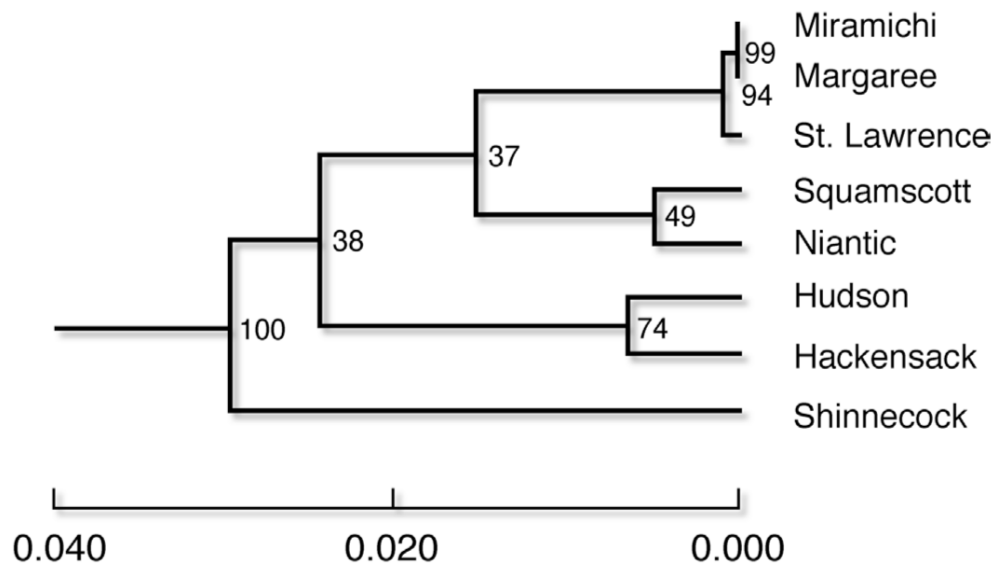

Fig. 2.

UPGMA (unweighted pair group method with arithmetic mean) population dendrogram based on genetic distances from mtDNA control region sequence data for tomcod from seven Atlantic Coast estuaries. Bootstrap support is on the dendrogram nodes. 
A

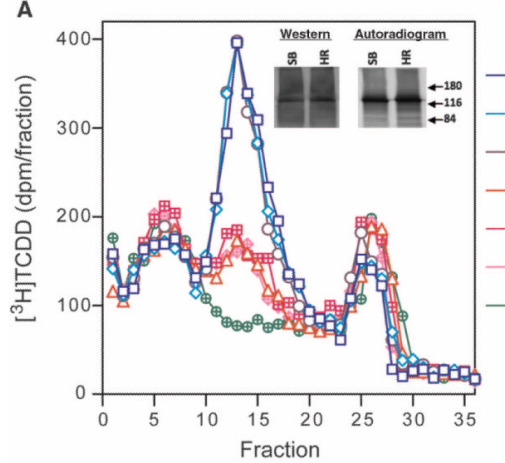

B

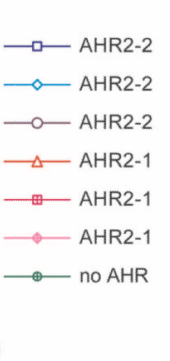



\section{C}



Fig. 3.

Comparison of variant AHR2 proteins in binding $\left[{ }^{3} \mathrm{H}\right] \mathrm{TCDD}$. (A) In vitro-expressed AHR2-1 and AHR2-2 proteins were incubated with $\left[{ }^{3} \mathrm{H}\right] \mathrm{TCDD}$, and specific binding was assessed by velocity sedimentation on sucrose gradients. Nonspecific binding was measured as the binding of $\left[{ }^{3} \mathrm{H}\right]$ TCDD to unprogrammed lysate containing vector with no insert. Synthesis was evaluated by autoradiography of ${ }^{35} \mathrm{~S}$-labeled AHR2 proteins and Western blotting using antibody to tomcod AHR2 (inset). (B) Specific binding of tomcod AHR2-1 and AHR2-2 proteins to $\left[{ }^{3} \mathrm{H}\right]$ TCDD (means \pm SD of three replicates). (C) Saturation binding analysis. AHR2-1 and AHR2-2 proteins were incubated with $\left[{ }^{3} \mathrm{H}\right] \mathrm{TCDD}$ (0.1 to $\left.12 \mathrm{nM}\right)$, and specific binding was assessed by velocity sedimentation on sucrose gradients. dpm, disintegrations per minute. The $\mathrm{K}_{\mathrm{d}}$ for binding of $\left[{ }^{3} \mathrm{H}\right] \mathrm{TCDD}$ to AHR2-2 is $1.27 \mathrm{nM}$. The $\mathrm{K}_{\mathrm{d}}$ for AHR2-1 could not be calculated. 


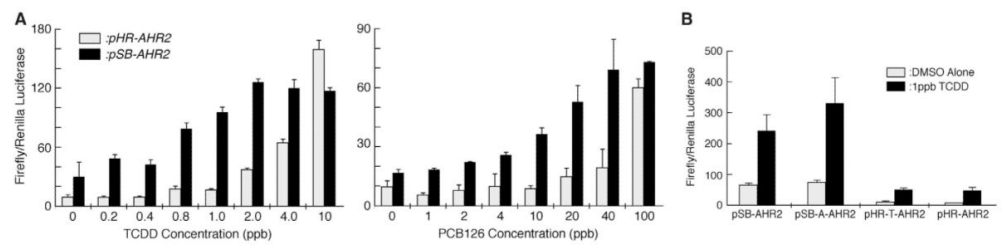

Fig. 4.

(A) Functional evaluation of AHR2 proteins in reporter gene assays. Expression was quantified in AHR-deficient cells transfected with $p S B-A H R 2$ or $p H R$-AHR2expressing AHR2 proteins and treated with graded doses of TCDD or PCB126. Values are the ratio of firefly to Renilla luciferase units (means \pm SD of four replicates). ppb, part per billion. (B) Evaluation of the AHR2 6-bp deletion and nt 3274 substitution in conferring resistance in reporter gene assays. Cells were transfected with $p S B-A H R 2$ (without deletion; $\mathrm{T}$ at $\mathrm{nt}$ 3274), $p H R-A H R 2$ (with deletion; A at nt 3274), $p S B-A-A H R 2$ (without deletion; A at nt 3274), or $p H R-T-A H R 2$ (with deletion; $\mathrm{T}$ at nt 3274) and treated with TCDD (1 ppb) (means \pm SD of four replicates). DMSO, dimethyl sulfoxide. 